
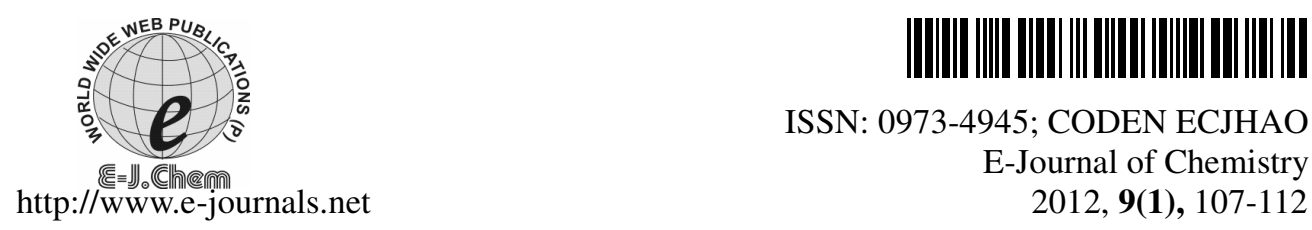

ISSN: 0973-4945; CODEN ECJHAO

E-Journal of Chemistry

2012, 9(1), 107-112

\title{
Theoretical Investigation of Solvation Effects on the Tautomerism of Maleic Hydrazide
}

\author{
MEISAM SHABANIAN ${ }^{\S *}$, HASSAN MOGHANIAN ${ }^{\#}$, \\ MOHSEN HAJIBEYGI and AZIN MOHAMADI ${ }^{\S}$ \\ ${ }^{\S}$ Young Researchers Club, Arak Branch \\ Islamic Azad University, Arak, Iran \\ \#Department of Chemistry, Dezful Branch \\ Islamic Azad University, Dezful, Iran \\ Department of Chemistry, Varamin-Pishva Branch \\ Islamic Azad University, Varamin-Pishva, Iran \\ m-shabanian@phd.araku.ac.ir
}

Received 28 May 2011; Accepted 5 August 2011

\begin{abstract}
A DFT study is used to calculate structural data of tautomers of maleic hydrazide $(\mathrm{MH})$ in the gas phase and selected solvents such as benzene (non-polar solvent), tetrahydrofuran (polar aprotic solvent) and methanol (protic solvent), dimethyl sulfoxide (polar aprotic solvent) and water (protic solvent) using PCM model. All tautomers are optimized at the B3LYP/6$31++\mathrm{G}(\mathrm{d}, \mathrm{p})$. The results show that the tautomer $\mathrm{MH}_{2}$ except in methanol is more stable than the other tautomers but in methanol $\mathrm{MH}_{5}$ (Diol) is more stable. In addition, stability of the tautomers in deferent solvents shows interesting results. Variation of dipole moments and NBO charges on atoms in the solvents were studied.
\end{abstract}

Keywords: DFT study, NBO analysis, PCM model, Maleic hydrazide, Tautomerism

\section{Introduction}

Tautomerism interconversions ${ }^{1-2}$ have been investigated by chemists during last decades. Recently, study of tautomerism received renewed attention due to its importance on determination of compounds' properties and their area of applications. The importance of tautomerism is revealed more since in recent years the investigation about tautomerism has been the major topic in theoretical chemistry. For example, tautomerisms in keto-enol ${ }^{3,4}$, imine-enamine ${ }^{5,6}$ and many other systems ${ }^{7}$ have been studied during past decades.

Tautomerisation and proton transfer of the keto-enol tautomer of heterocyclic systems with several basic centers, $\mathrm{N}, \mathrm{O}$ and $\mathrm{S}$ atoms, are of great interest to medicinal and biochemical 
applications. Also, understanding of the relative stabilities of heterocyclic tautomers and any subsequent conversions between tautomeric forms is very vital for both structural chemists and biologists ${ }^{8,9}$. Along this line, relative stabilities of various tautomeric structures of five-, six- and seven-member heterocyclic rings were investigated using both theoretical and experimental tools ${ }^{10-14}$.

1,2-Dihydropyridazine-3,6-dione (Maleic hydrazide) uses as a plant-growth inhibitor ${ }^{15}$. The similarity between molecular structure of maleic hydrazide and that of pyrimidine bases suggests erroneous incorporation into nucleic acid as a possible mechanism of action ${ }^{16}$. Like nucleic acid bases, maleic hydrazide shows some tautomers ${ }^{17,18}$.

The common studies of tautomerisation of carbonylic compounds such as hydantoin, uracil, thiouracil, 1, 2, 4-triazepines, oxazolidine and hydantoins, can anticipate that maleic hydrazide may exhibit five different tautomeric structures with different conformations. These tautomers have been covered extensively in the literature. However, this study employs density functional theory (DFT) on the investigation of those structures and to present a complete analysis of their relative stabilities in the gas phase and deferent solution. This work includes variation of dipole moments and NBO charges on atoms in the solvents and gas phase.

\section{Experimental}

All these calculations were carried out on a Pentium V personal computer by means of GAUSSIAN03 program package ${ }^{19}$ and for our computations. First, all compound's structures were drawn using Gauss View $03^{20}$ and optimized in semi-emprical methods. To characterize all the optimized geometries the vibrational frequencies for all the conformers have been done at $\mathrm{B}_{3} \mathrm{LYP}$ levels. The stationary structures are confirmed by ascertaining that all ground states have only real frequencies. The tautomers were also optimized in solvents according to the polarisable continuum method of Tomasi and co-workers, which exploits the generating polyhedra procedure $\mathrm{e}^{21-24}$ to build the cavity in the polarisable continuum medium, where the solute is accommodated. Atomic charges in all the structures were obtained using the Natural Population Analysis (NPA) method within the Natural Bond Orbital (NBO) approach ${ }^{25-27}$.

\section{Results and Discussion}

\section{Gas phase}

Structures and numbering of maleic hydrazide are depicted in Figure 1 and the results of energy comparisons of five tautomers in the gas phase and different solvents are given in Table 1. In the gas phase $\mathrm{MH}_{2}$ forms are more stable than the other forms. The major difference between $\mathrm{MH}_{2}$ and the other forms in gas phase was found for $\mathrm{MH}_{1}$ with $40.60 \mathrm{kcal} \mathrm{mol}^{-1}$. The order of stability of all the tautomers in the gas phase is $\mathrm{MH}_{2}>\mathrm{MH}_{4}>\mathrm{MH}_{5}>\mathrm{MH}_{3}>\mathrm{MH}_{1}$.

Table 1. Total energies at B3LYP/6-31++ ${ }^{* *}$ and relative stability in the gas phase and solvents

\begin{tabular}{ccccc}
\hline Tautomer & Gas (1.0) & Benzene (2.2) & THF (7.6) & Methanol (33) DMSO (46.7) Water (78.4) \\
\hline $\mathrm{MH}_{1}$ & 414.7246325414 .7366826 & 414.7450211 & 414.7482222414 .7483539414 .7489765 \\
$\mathrm{MH}_{2}$ & 414.7893364 & 414.8045766 & 414.8148037 & 414.8148037414 .8187938414 .8193252 \\
$\mathrm{MH}_{3}$ & 414.7289362 & 414.7384611 & 414.7449898 & 414.7474751414 .7475604 \\
$\mathrm{MH}_{4}$ & 414.7797625 & 414.7797629 & 414.8110299 & 414.8160292414 .8164571414 .8170376 \\
$\mathrm{MH}_{5}$ & 414.7804313 & 414.79444 & 414.8036373 & 414.8703310414 .8071745414 .8079169 \\
\hline
\end{tabular}




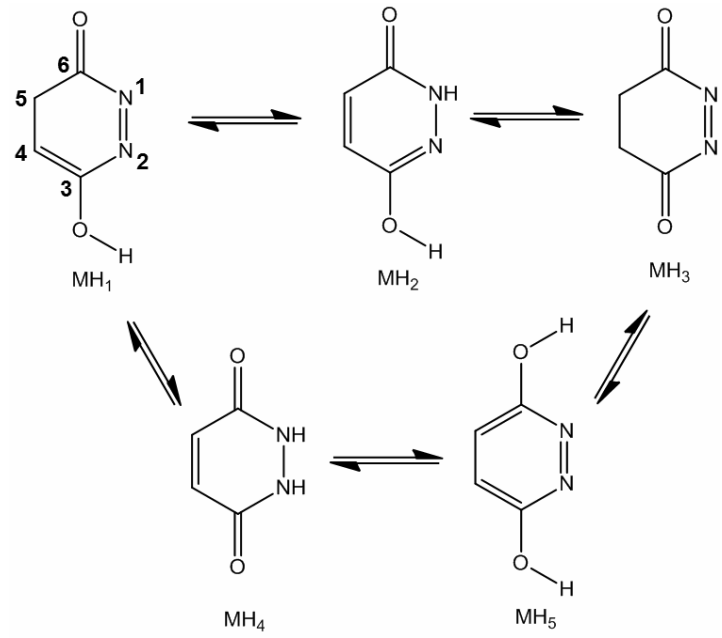

Figure 1. Tautomeric forms of maleic hydrazide and numbering of maleic hydrazide ring

This indicates that due to the $\mathrm{N}=\mathrm{N}, \mathrm{MH}_{3}$ and $\mathrm{MH}_{2}$ are less stable in the gas phase. Table 2 shows deference stability between all the tautomers.

Table 2. Energy ${ }^{\text {a }}$ difference between the tautomers of maleic hydrazide

\begin{tabular}{cccccccc}
\hline Tautomer & Gas (1.0) & Benzene (2.2) & THF (7.6) & & Methanol (33) DMSO (46.7) & Water (78.4) \\
\hline $\mathrm{MH}_{1}$ & 0.0647039 & 0.067894 & 0.0697826 & 0.1221088 & 0.0704399 & 0.0703487 \\
$\mathrm{MH}_{2}$ & 00.000 & 00.000 & 00.000 & 0.0555273 & 00.000 & 00.000 \\
$\mathrm{MH}_{3}$ & 0.0604002 & 0.0661155 & 0.0698139 & 0.1228559 & 0.0712334 & 0.0712986 \\
$\mathrm{MH}_{4}$ & 0.0095739 & 0.0248137 & 0.0037738 & 0.0543018 & 0.0023367 & 0.0022876 \\
$\mathrm{MH}_{5}$ & 0.0089051 & 0.0101366 & 0.0111664 & 00.000 & 0.0116193 & 0.0114083 \\
\hline
\end{tabular}

${ }^{a}$ Hartree.

The calculated dipole moments for the maleic hydrazide are presented in Table $3 . \mathrm{MH}_{4}$ tautomer has smaller dipole moments than the other forms and $\mathrm{MH}_{3}$ tautomer with $\mathrm{N}=\mathrm{N}$

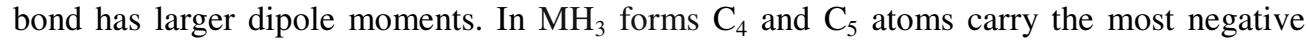
charge. It is noticeable that the differences between dipole moments of $1-\mathrm{H}$ and $2-\mathrm{H}$ forms are related to the double bond position.

Table 3. Calculated dipole moments of optimized tautomers of maleic hydrazide (Debye)

\begin{tabular}{ccccccc}
\hline Tautomer & Gas (1.0) & Benzene (2.2) & THF (7.6) & Methanol (33) & DMSO (46.7) & Water (78.4) \\
\hline $\mathrm{MH}_{1}$ & 3.7234 & 4.6765 & 5.4906 & 5.8379 & 5.8727 & 5.9094 \\
$\mathrm{MH}_{2}$ & 3.3043 & 4.1845 & 4.9084 & 4.9084 & 5.2268 & 5.2518 \\
$\mathrm{MH}_{3}$ & 4.7463 & 5.4312 & 5.9364 & 6.1246 & 6.1407 & 6.1566 \\
$\mathrm{MH}_{4}$ & 1.0016 & 1.0043 & 2.5719 & 2.7664 & 2.7862 & 2.8084 \\
$\mathrm{MH}_{5}$ & 1.6106 & 1.9427 & 2.2090 & 2.2925 & 2.3220 & 2.3101 \\
\hline
\end{tabular}

The calculated values NBO charges using the natural population analysis (NPA) of optimized structures of maleic hydrazides tautomers in the gas phase and solvents are listed in Table 4. In $\mathrm{MH}_{1} \mathrm{C} 5$ atom carries the largest negative charge, in $\mathrm{MH}_{2}, \mathrm{MH}_{4}$ and $\mathrm{MH}_{5}$ nitrogen atoms at position 1 or 2 carry the largest negative charge, in $\mathrm{MH}_{3}$ carbon atoms at position 4 or 5 carry the largest negative charge and these positions will most effectively interact with electrophiles. 
Table 4. Calculated NBO charges on ring atoms of maleic hydrazide

\begin{tabular}{|c|c|c|c|c|c|c|c|}
\hline Atom & & N1 & N2 & C3 & $\mathrm{C} 4$ & $\mathrm{C} 5$ & C6 \\
\hline$\epsilon=$ & \multirow{7}{*}{$\mathrm{MH}_{1}$} & & & & & & \\
\hline 1.0 & & -0.195 & -0.180 & 0.403 & -0.239 & -0.587 & 0.654 \\
\hline 2.2 & & -0.223 & -0.177 & 0.401 & -0.217 & -0.596 & 0.666 \\
\hline 7.6 & & -0.248 & -0.174 & 0.400 & -0.197 & -0.603 & 0.673 \\
\hline 33 & & -0.259 & -0.172 & 0.400 & -0.187 & -0.606 & 0.676 \\
\hline 46.7 & & -0.260 & -0.173 & 0.400 & -0.186 & -0.606 & 0.676 \\
\hline 78.4 & & -0.261 & -0.172 & 0.400 & -0.186 & -0.606 & 0.677 \\
\hline 1.0 & \multirow{5}{*}{$\mathrm{MH}_{2}$} & -0.422 & -0.316 & 0.488 & -0.251 & -0.244 & 0.590 \\
\hline 2.2 & & -0.419 & -0.326 & 0.494 & -0.248 & -0.249 & 0.592 \\
\hline 7.6 & & -0.415 & -0.331 & 0.499 & -0.245 & -0.253 & 0.592 \\
\hline 33 & & -0.415 & -0.331 & 0.499 & -0.245 & -0.253 & 0.592 \\
\hline 46.7 & & -0.414 & -0.333 & 0.501 & -0.243 & -0.255 & 0.592 \\
\hline 78.4 & \multirow{7}{*}{$\mathrm{MH}_{3}$} & -0.413 & -0.333 & 0.501 & -0.243 & -0.255 & 0.592 \\
\hline 1.0 & & -0.160 & -0.148 & 0.647 & -0.550 & -0.560 & 0.652 \\
\hline 2.2 & & -0.170 & -0.156 & 0.663 & -0.554 & -0.565 & 0.670 \\
\hline 7.6 & & -0.175 & -0.164 & 0.675 & -0.558 & -0.567 & 0.681 \\
\hline 33 & & -0.178 & -0.167 & 0.679 & -0.559 & -0.568 & 0.686 \\
\hline 46.7 & & -0.178 & -0.167 & 0.679 & -0.559 & -0.568 & 0.686 \\
\hline 78.4 & & -0.178 & -0.167 & 0.680 & -0.559 & -0.568 & 0.687 \\
\hline 1.0 & \multirow{5}{*}{$\mathrm{MH}_{4}$} & -0.469 & -0.469 & 0.612 & -0.247 & -0.247 & 0.612 \\
\hline 2.2 & & -0.468 & -0.468 & 0.612 & -0.247 & -0.247 & 0.612 \\
\hline 7.6 & & -0.430 & -0.430 & 0.606 & -0.249 & -0.249 & 0.606 \\
\hline 33 & & -0.426 & -0.426 & 0.606 & -0.249 & -0.249 & 0.606 \\
\hline 46.7 & & -0.426 & -0.426 & 0.606 & -0.250 & -0.250 & 0.606 \\
\hline 78.4 & \multirow{7}{*}{$\mathrm{MH}_{5}$} & -0.425 & -0.425 & 0.606 & -0.250 & -0.250 & 0.606 \\
\hline 1.0 & & -0.309 & -0.309 & 0.483 & -0.251 & -0.251 & 0.483 \\
\hline 2.2 & & -0.332 & -0.332 & 0.488 & -0.251 & -0.251 & 0.488 \\
\hline 7.6 & & -0.349 & -0.349 & 0.492 & -0.250 & -0.250 & 0.492 \\
\hline 33 & & -0.355 & -0.355 & 0.494 & -0.250 & -0.250 & 0.494 \\
\hline 46.7 & & -0.356 & -0.356 & 0.494 & -0.250 & -0.250 & 0.494 \\
\hline 78.4 & & -0.356 & -0.356 & 0.494 & -0.250 & -0.250 & 0.494 \\
\hline
\end{tabular}

Solvent effects

Solvent effects are relevant in tautomers stability phenomena, since polarity differences among tautomers can induce significant changes in their relative energies in solution. PCM/B3LYP calculations were used to analyze the solvent effects on tautomerism of maleic hydrazides. It is important to stress that the PCM model does not consider the presence of explicit solvent molecules; hence specific solute-solvent interactions are not described and the calculated solutions effects arise only from mutual solute-solvent electrostatic polarization. The data presented in Table 1 show that polar solvents increase the stability of all maleic hydrazide tautomers in compare to gas phase. The difference between the total energies of maleic hydrazide and the other forms do not show a regular trend when changing from gas phase to most polar solvents (water).

The solvent interactions have pronounced effect on the order of stability of the tautomers in the gas phase. For example, in benzene with low dielectric constant, order of 
stabilities of $\mathrm{MH}_{5}$ more stable than $\mathrm{MH}_{4}$ form and it can be due to strong interaction between benzene and aromatic ring in $\mathrm{MH}_{5}$ tautomer, in THF, DMSO and water solvents as polar solvents $\mathrm{MH}_{1}$ more stable than $\mathrm{MH}_{3}$ and the order of stability of all the tautomers is $\mathrm{MH}_{2}>\mathrm{MH}_{4}>\mathrm{MH}_{5}>\mathrm{MH}_{1}>\mathrm{MH}_{3}$, but in methanol $\mathrm{MH}_{5}$ is more stable than the other tautomers, it is my be due to strong hydrogen bond interaction between methanol and hydroxyl group in $\mathrm{MH}_{5}$ tautomer and after that $\mathrm{MH}_{4}$ is more stable than the other tautomers. The solvent represented by a polarizable continuum is found shows significant effect on the dipole moments of the individual solute conformers. The dipole moments increases by changing the gas phase to the solution as well as by increasing the solvent polarity. The most significant variations being obtained in $\mathrm{MH}_{3}$ form with $6.1566 \mathrm{D}$ (Table 3). In addition, in gas phase and benzene $\mathrm{MH}_{5}$ tautomers has higher dipole moment than $\mathrm{MH}_{4}$ forms but in polar solvents (THF, methanol, DMSO and water), $\mathrm{MH}_{4}$ tautomer has higher dipole moment than $\mathrm{MH}_{5}$ form. We have examined the charge distribution of tautomers in the solvent as well as gas phase by using calculated NBO charges. The charge distribution in solvents with increase of polarity differently varies for any atoms.

\section{Conclusion}

The following points emerge from the present study:

1. In the gas phase $\mathrm{MH}_{2}$ form was more stable than the other tautomers. In the solution the stability of some tautomers is deferent than gas phase and stability of tautomers were affected by deferent solvents. With increase of polarity total energy of all compounds were more negative.

2. The dipole moments of all compounds are affected by solvent. With increase of the polarity of solvents the dipole moments of all tautomers were increased.

3. The charges on all six positions were affected by solvents. In addition with increase of dielectric constant a variation was found.

\section{References}

1 Grochowski J, Serda P, Markiewicz M, Kozik B and Sepiol J J, J Mol Struct., (Theochem.), 2004, 689, 43-48.

2 Belova N V, Oberhammer H, Girichev G V and Shlykov S A, J Phys Chem A., 2008, 112(14), 3209-3214.

3 Misra A and Dalai S, J Mol Struct., (Theochem.), 2007, 807, 33.

4 Zborowski K and Korenova A, Theochem., 2004, 683, 15.

5 Oziminski W P, Dobrovolski J C and Mazurek A P, J Mol Struct. (Theochem.),2004, 680, 107.

6 Dines T J and Onoh H, Spectrochim Acta A, 2006, 64, 891.

7 Bonacin J A, Formiga A L B, de Melo V H S and Toma H E, Vib Spectrosc., 2007, 44(1), 133-141.

8 Elguero J, Katritzky A R and Denisko O V, Adv Heterocycl Chem., 2000, 76, 1.

9 Minkin V I, Garnovski A D, Elguero J, Katritzky A R and Denisko O, Adv Heterocycl Chem., 2000, 76, 157-323.

10 Tahmassebi D, J Mol Struct., (Theochem)., 2003, 638, 11-20.

11 Agelova S, Enchev V, Markova N, Denkova P and Kostova K, J Mol Struct., (Theochem)., 2004, 711, 201.

12 Santos M, Junior M, Oliviera S, da Silva J, Lima M, Lima M, Galdino S and Pitta I, $J$ Mol Struct., (Theochem)., 2005, 715, 191.

13 Yu F L, Schwalbe C H and Watkin D, Acta Cryst., 2004, 60, 714-717. 
14 Lamsabhi M, El Messaoudi T, Esseffar M, Esseffar, Alcami M and Yanez M, New J Chem., 2002, 26, 711.

15 Hofmann H J, Cimiraglia R, Tomasi J and Bonaccorsi R, J Mol Struct (Theochem)., 1991, 227, 321-326.

16 Cradwick P D, Nature, 1975, 258, 774.

17 Elguero J, Marzin C, Katritzky A R and Linda P, Adv Heterocycl Chem., Suppl. 1: The Tautomerism of Heterocycles, Academic Press, New York, 1976, p. 124.

18 Tisler M and Stanovnik B, in Katritzky A R and Rees C W, (Eds)., Comprehensive Heterocyclic Chemistry, Pergamon Press, Oxford, 1984, 3, 52.

19 Frisch M J, et al. Gaussian 03, Revision C02, 2004, Gaussian, Inc, Wallingford CT

20 Dennington R, Keith T, Millam J, Eppinnett K, Hovell W L and Gilliland R, Gauss View, Version 309. Semichem, Inc, Shawnee Mission, KS, 2003.

21 Miertus S, Scrocco E and Tomasi J, J Chem Phys., 1981, 55, 117.

22 Cances M T, Mennucci V and Tomasi J, J Chem Phys., 1997, 107, 3032-3037.

23 Cossi M, Barone V, Mennucci B and Tomasi J, Chem Phys Lett., 1998, 286, 253-260.

24 Barone V, Cossi M and Tomasi J, J Comp Chem., 1998, 19, 404-417.

25 Barone V and Cossi M, J Phys Chem A, 1998, 102, 1995-2001.

26 Reed A E, Curtiss L A and Wienhold F, Chem Rev., 1988, 88, 899-926.

27 Najafi Chermahini A, Nasr-Esfahani M, Dalirnasab Z, Abdol Dabbagh H and Teimouri A, J Mol Struct., (Theochem)., 2007, 820, 7. 


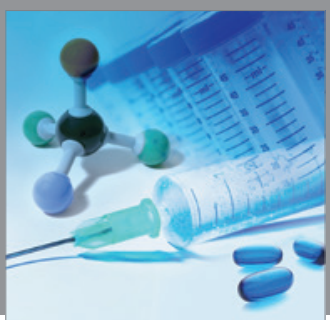

International Journal of

Medicinal Chemistry

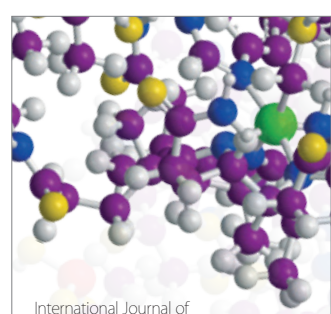

Carbohydrate Chemistry

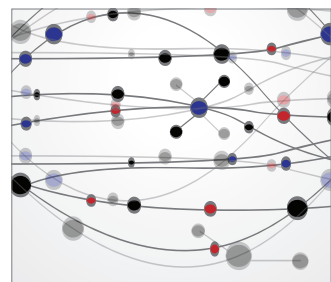

The Scientific World Journal
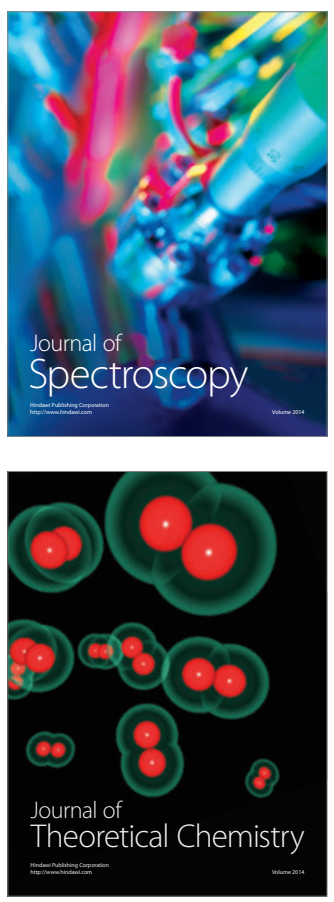
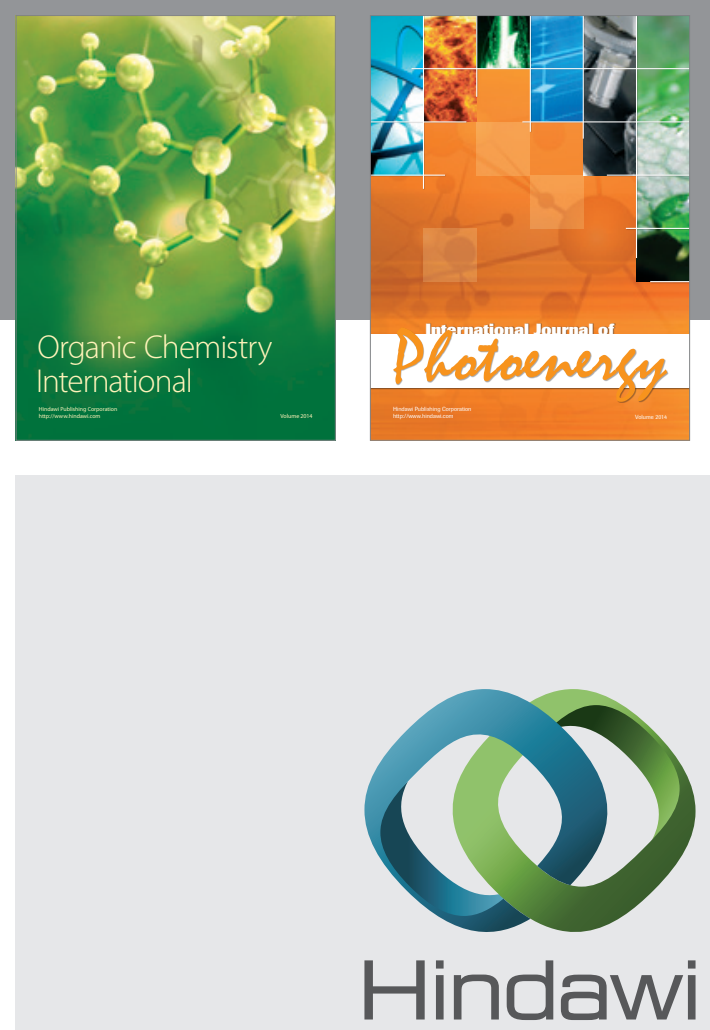

Submit your manuscripts at

http://www.hindawi.com
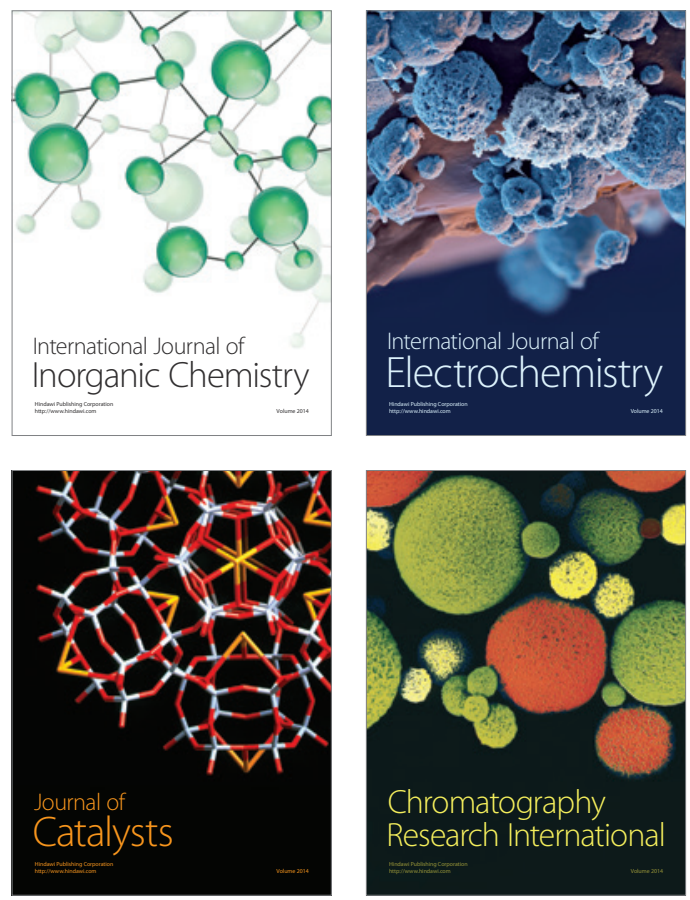
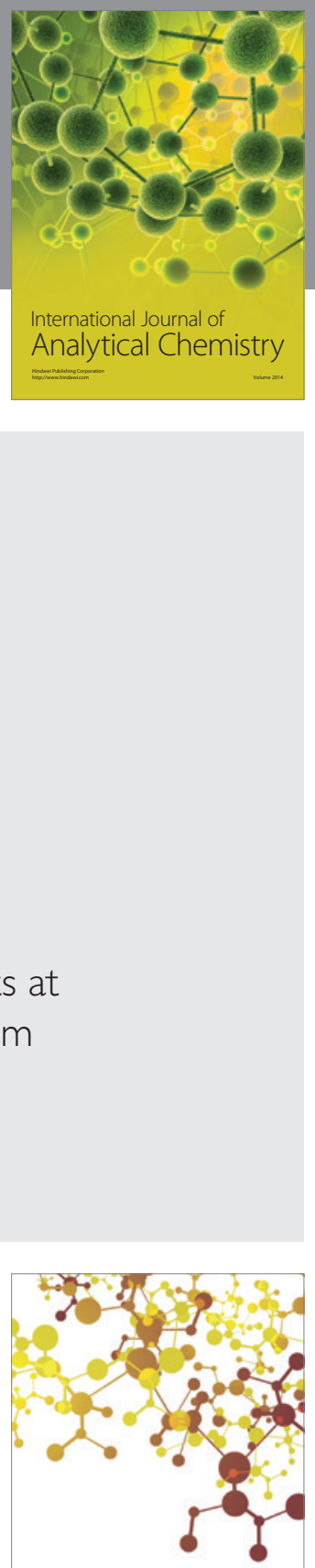

Journal of

Applied Chemistry
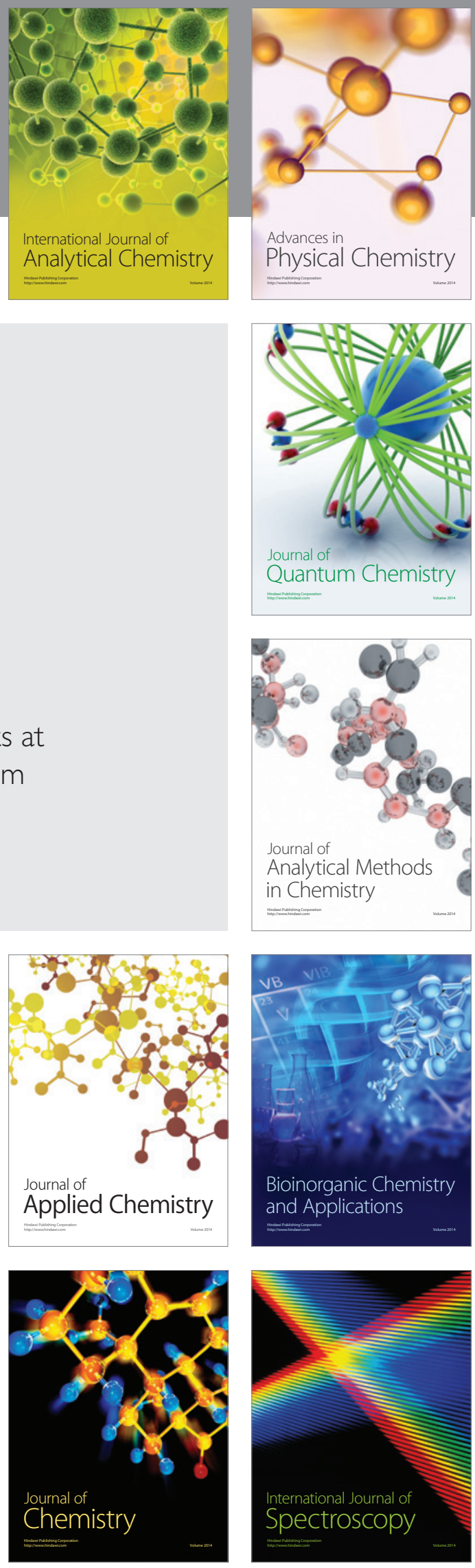